\title{
Gonadotropin releasing hormone agonists are effective in long-term treatment of women with abnormal uterine bleeding and anticoagulant therapy: Report of 3 cases and review of the literature
}

\author{
Rakia Aljasser ${ }^{1,2}$, Angelos G Vilos ${ }^{1}$, Basim Abu-Rafea ${ }^{1}$ and George A Vilos ${ }^{1 *}$ \\ ${ }^{1}$ The Fertility Clinic, London Health Sciences Center, Department of Obstetrics and Gynecology, Division of Reproductive Endocrinology and Infertility, Western \\ University, London, Canada \\ ${ }^{2}$ Department of Obstetrics and Gynecology, King Khalid University Hospital, King Saud University, Riyadh, Saudi Arabia
}

\begin{abstract}
Objectives: To evaluate the efficacy of $\mathrm{GnRH}$ agonists ( $\mathrm{GnRH}-\mathrm{a})$ in women with abnormal uterine bleeding (AUB) on anticoagulant therapy.

Materials and Methods: Prospective observational case series (Canadian Task Force Classification II-3) at a University affiliated teaching hospital. From January 2002 through July 2019, three premenopausal women with AUB on warfarin therapy were identified in our clinic. After clinical assessment, including Papanicolaou smear, endometrial biopsy, and pelvic sonography, a GnRH-a was used to treat their AUB.

Results: Two women were receiving warfarin therapy $(5-7 \mathrm{mg} / \mathrm{d})$ for previous venous thromboembolism and one for mechanical heart valve replacement associated with Marfan's syndrome. All patients had significant additional comorbid conditions and were at high risk for traditional medical or surgical therapies. After treatment with GnRH-a, all women reported significant menstrual reduction at 3 months and remained amenorrhoeic for 2 to 11 years; two of whom reached menopause.
\end{abstract}

Conclusion: In properly assessed and selected premenopausal women with AUB receiving anticoagulant therapy and at high risk for traditional therapies, long-term GnRH-a were effective treatment in 3 patients.

\section{Introduction}

Abnormal uterine bleeding (AUB) is any departure from a normal menstruation pattern. The key characteristics of AUB are irregularity, and changes in frequency or the amount of menstrual blood and/or the duration of flow; but each of these may exhibit considerable variability [1]. In general, AUB is experienced by approximately $20 \%$ to $30 \%$ of premenopausal women [2] and is a common debilitating condition that results in reduced hemoglobin, it adversely affects quality of life, and is associated with significant use of health care resources [3].

Gynecologists managing women presenting with AUB may be faced with medical and/or anatomical conditions that, in conjunction with factors such as age, hormonal, metabolic, and body mass index (BMI), may contribute to AUB. Among these conditions are congenital or iatrogenic bleeding disorders, cardiovascular conditions requiring prostheses, thromboembolic events requiring acute thrombolysis and/ or long term thromboprophylaxis and cerebrovascular accidents. Traditional therapies for AUB, under these circumstances, may be ineffective, refused, contraindicated, difficult or risky to administer.

Herein, we report our experience with 3 women with AUB, and various comorbidities and conditions requiring long-term anticoagulation therapy treated with long-term GnRH-a with or without add back therapy.

\section{Materials and methods}

From January 2002 through July 2019, three premenopausal women with AUB on warfarin therapy were identified in our clinic. After clinical assessment, including Papanicolaou smear, endometrial biopsy, and pelvic sonography, a GnRH-a was used to treat their AUB.

The study was approved by our University ethics committee (Clinical outcomes of women with abnormal uterine bleeding (AUB) treated by endometrial ablation and other medical therapies -HSREB 4913) and all 3 women signed consent to publish their case.

${ }^{*}$ Correspondence to: George A Vilos, The Fertility Clinic, London Health Sciences Center, Department of Obstetrics and Gynecology, Division of Reproductive Endocrinology and Infertility, Western University, London, Canada, Tel: 519-646-6104; Fax: 519-646-6345; E-mail: george.vilos@lhsc.on.ca

Key words: abnormal uterine bleeding, anticoagulation, gonadotropin releasing hormone agonist, heavy menstrual bleeding, menorrhagia, warfarin

Received: November 17, 2019; Accepted: November 26, 2019; Published: November 29, 2019 
Aljasser R (2019) Gonadotropin releasing hormone agonists are effective in long-term treatment of women with abnormal uterine bleeding and anticoagulant therapy: Report of 3 cases and review of the literature

Table 1. Demographics, presentation, treatment and clinical outcomes of three women with AUB and anticoagulant therapy.

\begin{tabular}{|c|c|c|c|c|c|}
\hline Case & $\begin{array}{l}\text { Age } \\
\text { (Years) }\end{array}$ & $\begin{array}{l}\text { BMI } \\
\mathbf{K g} / \mathbf{m}^{2}\end{array}$ & Presentation/comorbidities & Treatment & Outcome \\
\hline 1 & 40 & 24 & $\begin{array}{l}\text { AUB } \\
\text { SLE } \\
\text { Lupus anticoagulant } \\
\text { Two episodes of DVT }\end{array}$ & $\begin{array}{l}\text { Failed endometrial ablation } \\
\text { Leuprolide acetate } 11.25 \mathrm{mg} \text { every } 3 \text { months plus } 1 \\
\text { mg Estrace and } 100 \mathrm{mg} \text { Prometrium daily }\end{array}$ & $\begin{array}{l}11 \text { years: } \\
\text { Amenorrhea, Menopause }\end{array}$ \\
\hline 2 & 54 & 42 & $\begin{array}{l}\text { AUB } \\
\text { Two episodes of DVT } \\
\text { Unprovoked PE } \\
\text { Morbid obesity } \\
\text { Hypertension } \\
\text { Type-2 diabetes } \\
\text { Gastroesophageal reflux } \\
\text { Sleep apnea }\end{array}$ & $\begin{array}{l}\text { Failed LNG-IUS } \\
\text { Failed DMPA } \\
\text { Goserelin } 10.8 \text { mg every } 3 \text { months }\end{array}$ & $\begin{array}{l}2 \text { years: Amenorrhea, } \\
\text { Menopause }\end{array}$ \\
\hline 3 & 39 & 35 & $\begin{array}{l}\text { AUB } \\
\text { Marfan's syndrome } \\
\text { Prosthetic aortic valve } \\
\text { Multiple surgical procedures for aortic dissection } \\
\text { and thoracoabdominal aneurysm } \\
\text { Amaurosis fugax } \\
\text { Hypertension } \\
5 \text { Transient ischemic attacks } \\
\text { Psoriatic arthritis }\end{array}$ & $\begin{array}{l}\text { Goserelin } 10.8 \mathrm{mg} \text { every } 3 \text { months plus add-back } \\
\text { therapy norethindrone acetate } 5 \mathrm{mg} / \text { day }\end{array}$ & $\begin{array}{l}3 \text { years: } \\
\text { Amenorrhea }\end{array}$ \\
\hline
\end{tabular}

AUB: abnormal uterine bleeding; SLE: systemic lupus erythematosus; DVT: deep venous thrombosis; PE: pulmonary embolism; LNG-IUS: levonorgestrel intrauterine system; DMPA: depomedroxyprogesterone acetate

\section{Results}

The patient demographics, presentation, treatment and clinical outcomes are summarized in Table 1 and additional details of each case are presented below.

\section{Case 1}

A 40-year-old woman, G3P2, BMI $24 \mathrm{~kg} / \mathrm{m}^{2}$, presented with AUB. She had been diagnosed with systemic lupus erythematosus (SLE) and carrier of lupus anticoagulant with history of two episodes of deep venous thrombosis (DVT). Consequently, she was on thromboprophylactic treatment using warfarin (Coumadin, BristolMyers Squibb, Montreal, QC) $5 \mathrm{mg}$ /day and hydroxychloroquine 200 mg daily by mouth (Plaquenil, Sanofi Canada, Laval, QC). Likely, the anticoagulation therapy was a contributor to her heavy vaginal bleeding and after discussing treatment options, she underwent endometrial ablation using a hot liquid thermal balloon (Thermablate, Idoman Canada, Toronto, Ontario).

Two years after endometrial ablation, she developed progressively increasing abnormal uterine bleeding resulting in iron deficiency anemia and required additional therapy. After appropriate counseling and consultation with a hematologist, she was started on GnRH-a therapy (Leuprolide acetate, Lupron, Abbvie Canada, Saint-Laurent, QC) ) $11.25 \mathrm{mg}$ intramuscular injections every 3 months along with add-back therapy using $1 \mathrm{mg}$ of $17 \mathrm{~B}$-estradiol (Estrace, Acerus Pharmaceuticals, Mississauga, ON) and $100 \mathrm{mg}$ of micronized progesterone (Prometrium, Merck Canada, Kirkland, QC) per day. At 11 years of follow up, she has remained amenorrheic and became menopausal at 51 years. At this time, we discontinued the GnRH-a and add back therapy but kept her anticoagulated indefinitely and reassess her annually.

\section{Case 2}

A 54-year-old woman, G6P6, BMI $42 \mathrm{~kg} / \mathrm{m}^{2}$, was referred with dysmenorrhea and iron deficiency anemia with hemoglobin of $80 \mathrm{~g} / \mathrm{L}$. She always had heavy menstrual bleeding, but it became progressively worse in the last 3 years following anticoagulant therapy. She had 2 episodes of deep vein thrombosis (DVT) and unprovoked pulmonary embolism (PE) three years prior and she was on $5 \mathrm{mg}$ of warfarin daily. A $52 \mathrm{mg}$ levonorgestrel intrauterine system (LNG-IUS, Mirena, Bayer, Mississauga, ON) had been tried for 6 months but it was removed for making her bleeding unpredictable. In the last 8 months, she had also been treated with a course of depomedroxyprogesterone acetate (DMPA, Pfizer, Mississauga, ON) $150 \mathrm{mg}$ intramuscular injections every three months but it was causing breakthrough bleeding and lower abdominal pain.

She had multiple medical conditions including, obesity (class 3 ), hypertension, diabetes type-2, gastroesophageal reflux, sleep apnea and bursitis for which she was taking multiple medications.

After assessment of her pelvic organs including an endometrial biopsy indicating pseudodecidualized endometrium, she agreed to be treated with GnRH-a and she was given goserelin (AstraZeneca, Mississauga, ON) $10.8 \mathrm{mg}$ subcutaneously every 3 months with iron supplements. After 3 months, she became amenorrhoeic and her hemoglobin increased to $132 \mathrm{~g} / \mathrm{L}$. At 2-years, she was doing well on goserelin injections with no reported vaginal bleeding and the treatment was stopped due to achieving natural menopause at 56 years.

\section{Case 3}

A 39-year-old woman, G0P0, BMI of $34.5 \mathrm{~kg} / \mathrm{m}^{2}$, presented with shortness of breath, chronic fatigue and heavy menstrual bleeding (HMB) associated with iron deficiency anemia with hemoglobin of 79 $\mathrm{g} / \mathrm{L}$. Her uterine bleeding was cyclic in nature every 30 days, lasting up to 7 days and described as heavy associated with clots and moderate to severe dysmenorrhea.

She had been diagnosed with polycystic ovarian syndrome (PCOs) and she provided a positive family history of Marfan's syndrome. The patient also had been diagnosed with atypical Marfan's syndrome and she had multiple surgical procedures including a Bentall procedure for a dissection of her aortic arch with mechanical aortic valve replacement. She also had an 'elephant trunk' procedure. After 10 months of the second procedure, her chronic thoracoabdominal dissection which extended down to the common iliac arteries and their bifurcation bilaterally, became quite complex with multiple lumens and she began developing pseudocoarctation symptoms. Therefore, she underwent 
Aljasser R (2019) Gonadotropin releasing hormone agonists are effective in long-term treatment of women with abnormal uterine bleeding and anticoagulant therapy: Report of 3 cases and review of the literature

thoracoabdominal aneurysm repair with cardiopulmonary bypass. Later, she developed amaurosis fugax from thrombi on her prosthetic aortic valve with decrease in maximum and mean gradient observed by echocardiography.

In addition, the patient was known to have hypertension, psoriatic arthritis, degenerative disc disease and provided a history of at least 5 transient ischemic attacks (TIA) for which, together with her mechanical aortic valve replacement, required life-time anticoagulation. Consequently, she was on warfarin, 5 to $7 \mathrm{mg}$ daily together with $81 \mathrm{mg}$ of aspirin daily in conjunction with antihypertensive medications.

Following appropriate history, physical examination and assessment of her AUB, the management of this patient became quite a challenge due to limited options for both traditional diagnostic tests and therapeutic modalities. Treatment options were even more challenging since traditional hormone therapies may be contraindicated in fully anticoagulated patients. Although there is some experience with anticoagulated patients treated with endometrial ablation using intrauterine balloons [4] and/or resectoscopic surgery [5], we decided that endometrial ablation was not an appropriate option for this patient being a high surgical risk and also being less than 40 years of age which is a known factor for increased ablation failure.

We have previously published good clinical outcomes with the use of LNG-IUS in women with AUB and anticoagulant therapy [6]. However, this patient refused our proposed treatment with LNG-IUS. As a result, we proposed long-term treatment with a $\mathrm{GnRH}$-a with add back therapy and she was treated with goserelin $10.8 \mathrm{mg}$ injections subcutaneously every 3 months and norethindrone acetate (NETA) $5 \mathrm{mg}$ daily. At 3-years of follow-up, the patient is amenorrhoeic, maintains a normal hemoglobin levels $(125 \mathrm{~g} / \mathrm{L})$ and she is satisfied with her treatment.

\section{Discussion}

Oral anticoagulation therapy has been reported to increase menstrual blood loss $[7,8]$, with $70 \%$ of women on anticoagulant therapy experiencing changes in their menstrual cycle. $50 \%$ experience a greater number of menstrual days, and $66 \%$ heavier menstrual bleeding, with a significant number of women experiencing flooding and passing clots [9].

Treatment of women with AUB and anticoagulant therapy can be challenging since both surgical and medical therapies may be refused, contraindicated or difficult to administer due to various comorbid conditions. Some of the treatments including surgical and medical interventions are discussed below.

\section{Endometrial ablation}

Thermal balloon endometrial ablation: We have previously reported on 11 high-risk surgical candidates with AUB and anticoagulant therapy (warfarin) treated with thermal balloon (ThermaChoice, Gynecare, J\&J, New Jersey) endometrial ablation without stopping their anticoagulant therapy. At a median follow up of 11 months, 7 (64\%) reported improvement in menstrual blood loss, 3 (27\%) of whom had amenorrhea [4].

Endometrial resectoscopic ablation: Goldenberg et al reported on 11 patients with hematologic disorders, who had AUB and failed medical therapy, treated with resectoscopic endometrial ablation. After one-year follow-up, the patient's satisfaction was high (10/11) with an average increase in hemoglobin level of $20 \mathrm{~g} / \mathrm{L}$ [5].

\section{Hormonal therapies}

In general, medical management of women with AUB include any one of or combinations of estrogens, progestins, androgens and $\mathrm{GnRH}$ agonists. However, the role of these agents in anticoagulated women with AUB has not been well determined and in fact, most, if not all of them, may be ineffective or contraindicated. Opinions on providing hormonal contraception and management of anticoagulant-associated bleeding in premenopausal patients with venous thromboembolism (VTE) risk, in clinical practice, are divergent and heterogeneous [10].

Estrogens: The use of estrogen in anticoagulated women requiring contraception remains controversial. According to the World Health Organization (WHO) guidelines, hormonal therapy with estrogen and the "use of estrogen-containing contraceptives confers an unacceptable health risk" during established anticoagulant treatment of women with venous thromboembolism" [11]. In contrast, the Scientific and Standardization Committee of the International Society on Thrombosis and Hemostasis recommends that women can continue oral contraceptive and estrogen replacement hormonal therapy while on anticoagulant therapy [12]. The latter was supported by an additional study which reported that hormonal therapy was not associated with an increased risk of recurrent VTE in women receiving therapeutic anticoagulation [13].

Progestins: Treatment with progestins or progestin-loaded IUS have been tried and are considered relatively safe as a first line of treatment for patients with multiple risk factors that preclude definitive surgical treatment such as hysterectomy.

Oral and injectable progestins: In a Cochrane review, women with AUB on oral cyclic progestin for 21 days had significantly less blood loss [14]. There were few studies on patients using anticoagulant therapy with oral or injectable progestin as contraceptive method. In terms of contraception, the WHO labelled oral and injectable progestin as category 2 (advantage outweigh risk) [11].

LNG-IUS: Few studies have described the use of LNG-IUS in anticoagulated women presenting with AUB $[6,15,16]$. A randomized trial divided 40 women with AUB receiving anticoagulant therapy in to receiving a LNG-IUS vs. no intervention. Women treated with the LNG-IUS had significant reduction in blood loss with increased hemoglobin level after 3 and 6 months follow up compared with the non-intervention group [15].

A prospective study by Vilos, et al. described 10 premenopausal women receiving warfarin therapy with $\mathrm{AUB}$ and no intrauterine pathology, treated with LNG-IUS. At 5 years, the LNG-IUS therapy remained effective in $70 \%$ of patients [6]. Although the use of the LNG-IUS had been reported to be an effective treatment in this group of women, in a survey conducted by Pisoni, et al. on 23 patients on anticoagulant using a LNG-IUS to treat menorrhagia, 17 only returned the questionnaire, $11.8 \%$ experienced worsening of bleeding and $5.9 \%$ had no improvement of their AUB [16].

\section{GnRH agonists}

The use of GnRH-a is one of the medical therapies for the management of AUB [17] inducing hypo-estrogenism and endometrial atrophy with subsequent improvement of hemoglobin levels [18].

To our knowledge, there are only two published case reports describing the management of heavy menstrual bleeding associated with anticoagulation using a GnRH-a $[19,20]$. The first case report described a patient with heavy menstrual bleeding and fibroid uterus 
Aljasser R (2019) Gonadotropin releasing hormone agonists are effective in long-term treatment of women with abnormal uterine bleeding and anticoagulant therapy: Report of 3 cases and review of the literature

who presented with unstable angina and was treated with anticoagulant therapy. After heparin therapy, her bleeding became extremely heavy and she was started on goserelin depot $3.6 \mathrm{mg}$ subcutaneously monthly, and warfarin simultaneously. The patient underwent a stent procedure and 2 months later the warfarin and goserelin therapies were stopped and the patient underwent hysterectomy [19].

Another case report described a patient with positive heterozygous Factor V Leiden on long-term anticoagulation after an episode of DVT and pulmonary embolism. Due to episodes of persistent AUB and decreased hemoglobin level, the patient was started on GnRH-a (leuprolide acetate $3.75 \mathrm{mg}$ monthly) for 3 months. During treatment, the uterine bleeding decreased but did not stop completely and the treatment was changed to a progestin intrauterine device placement and long-term oral progestin with improvement of the patient's AUB [20].

In our case series we report the use of GnRH-a in 3 fully anticoagulated patients at high risk of recurrent VTE and/or PE. They were satisfied without the need to discontinue their anticoagulant, no new VTE and they were in complete amenorrhea, two of whom reached menopause.

In two young patients who were less than 50 years old, we also provided add back therapy as long term use of GnRH-a have adverse effect on bone density [21] and add-back therapy was suggested to avert bone loss and vasomotor symptoms without nullifying the GnRH-a therapeutic effects [22,23]. Both estrogen/progestin and progestin only have been prescribed as add-back therapy with GnRH-a $[22,23]$. Norethindrone acetate is a unique only progestin used as add-back therapy, since it has both estrogenic and androgenic properties and effectively reduce $\mathrm{GnRH}$-a side effects [24,25].

Add-back therapy is a low dose hormone used to alleviate some of the side effect of GnRH-a while preserving its therapeutic efficacy. Current literature is mostly studying add-back therapy on patients with endometriosis or uterine fibroids, especially how to reduce the side effects of long-term use of GnRHa and hypoestrogenic state including progressive bone loss. In a prospective study, young women on $\mathrm{GnRH}-\mathrm{a}$ were followed for 1 year, patients who did not receive add-back treatment lost $6.3 \%$ of bone marrow density (BMD) [26]. In another randomized trial, add-back therapy with either norethindrone acetate $5 \mathrm{mg} /$ day alone or norethindrone acetate $5 \mathrm{mg}$ /day plus conjugated equine estrogens $0.625 \mathrm{mg} /$ day, successfully preserved bone health and improved quality of life [27].

\section{Conclusion}

In properly assessed and selected premenopausal women with AUB receiving anticoagulant therapy and at high risk for traditional therapies, long-term GnRH-a with and without add-back therapy, was an effective treatment in 3 patients. Weighing the risk of VTE and the risk of excessive bleeding should be kept in mind when treating women in reproductive age suffering from anticoagulation-associated heavy menstrual bleeding and each patient should have an individualize treatment.

\section{Disclosure statement}

The authors declare that they have no conflicts of interest and nothing to disclose

\section{Institutional review and patient consent}

Clinical outcomes of women with abnormal uterine bleeding (AUB) treated by endometrial ablation and other medical therapies HSREB 4913. All 3 women signed consent to publish their case.

\section{References}

1. Fraser IS, Critchley HO, Broder M, Munro MG (2011) The FIGO recommendations on terminologies and definitions for normal and abnormal uterine bleeding. Seminars in reproductive medicine 29: 383-390.

2. Singh S, Best C, Dunn S, Leyland N, Wolfman WL (2018) Abnormal uterine bleeding in pre-menopausal women. J Obstet Gynaecol Can 40: e391-e415.

3. National Guideline Alliance (UK) (2018) Heavy menstrual bleeding (update). London: National Institute for Health and Care Excellence, UK.

4. Aletebi FA, Vilos GA, Eskandar MA (1999) Thermal balloon endometrial ablation to treatment menorrhagia in high-risk surgical candidates. J Am Assoc Gynecol Laparosc 6: 435-439.

5. Goldenberg M, Zolti M, Hart S, Bider D (1998) Endometrial resectoscopic ablation in patients with menometrorrhagia as a side effect of anticoagulant therapy. Eur J Obstet Gynecol Reprod Biol 77: 77-79.

6. Vilos GA, Tureanu V, Garcia M, Abu-Rafea B (2009) The levonorgestrel intrauterine system is an effective treatment in women with abnormal uterine bleeding and anticoagulant therapy. J Minim Invasive Gynecol 16: 480-484.

7. Van Eijkeren M, Christiaens G, Haspels A, Sixma J (1991) Measured menstrual blood loss in women with a bleeding disorder or using oral anticoagulant therapy. Int $J$ Gynecol Obstet 34: 199.

8. Själander A, Friberg B, Svensson P, Stigendal L, Lethagen S (2007) Menorrhagia and minor bleeding symptoms in women on oral anticoagulation. J Thromb Thrombolysis 24: $39-41$.

9. Huq FY, Tvarkova K, Arafa A, Kadir RA (2011) Menstrual problems and contraception in women of reproductive age receiving oral anticoagulation. Contraception 84: 128132 .

10. Klok FA, Schreiber K, Stach K, Ageno W, Middeldorp S, et al. (2017) Oral contraception and menstrual bleeding during treatment of venous thromboembolism: Expert opinion versus current practice. Thromb Res 153: 101-107.

11. https://www.who.int/reproductivehealth/publications/family_planning/MEC-5/en/

12. Baglin T, Bauer K, Douketis J, Buller H, Srivastava A, et al. (2012) Duration of anticoagulant therapy after a first episode of an unprovoked pulmonary embolus or deep vein thrombosis: guidance from the SSC of the ISTH: Unprovoked VTE: duration of anticoagulation. J Thromb Haemost 10: 698-702.

13. Martinelli I, Lensing AWA, Middeldorp S, Levi M, Beyer-Westendorf J, et al. (2016) Recurrent venous thromboembolism and abnormal uterine bleeding with anticoagulant and hormone therapy use. Blood 127: 1417-1425.

14. Lethaby A, Irvine GA, Cameron IT (2008) Cyclical progestogens for heavy menstrual bleeding. Cochrane Database Syst Rev 2008: CD001016.

15. Kilic S, Yuksel B, Doganay M, Bardakci H, Akinsu F, et al. (2009) The effect of levonorgestrel-releasing intrauterine device on menorrhagia in women taking anticoagulant medication after cardiac valve replacement. Contraception 80: 152-157.

16. Pisoni CN, Cuadrado MJ, Khamashta MA, Hunt BJ (2006) Treatment of menorrhagia associated with oral anticoagulation: efficacy and safety of the levonorgestrel releasing intrauterine device (Mirena coil). Lupus 15: 877-880.

17. Colacurci N, De Placido G, Mollo A, Perino A, Cittadini E (1995) Short-term use of Goserelin depot in the treatment of dysfunctional uterine bleeding. Clin Exp Obstet Gynecol 22: 212-219.

18. Cetin NN, Karabacak O, Korucuoglu U, Karabacak N (2009) Gonadotropin-releasing hormone analogue combined with a low-dose oral contraceptive to treat heavy menstrual bleeding. Int J Gynecol Obstet 104: 236-239.

19. Khurana C, Taylor P, de Belder MA (1998) Corona stenting in a patient menorrhagia: use of a gonadotrophin releasing hormone agonist to facilitate anticoagulation. Int $J$ Cardiol 63: 89-91.

20. Giustozzi M, Vedovati MC, Agnelli G (2018) Management of heavy menstrual bleeding during direct oral anticoagulant therapy for recurrent venous thromboembolism: a case report. Blood Coagulation \& Fibrinolysis 29: 391-394.

21. Nencioni T, Penotti M, Barbieri-Carones M, Ortolani S, Trevisan C, et al. (1991) Gonadotropin releasing hormone agonist therapy and its effect on bone mass. Gynecol Endocrinol 5: 49-56.

22. Thomas EJ, Okuda KJ, Thomas NM (1991) The combination of a depot gonadotrophin releasing hormone agonist and cyclical hormone replacement therapy for dysfunctional uterine bleeding. Br J Obstet Gynaecol 98: 1155-1159. 
Aljasser R (2019) Gonadotropin releasing hormone agonists are effective in long-term treatment of women with abnormal uterine bleeding and anticoagulant therapy: Report of 3 cases and review of the literature

23. Thomas EJ (1996) Add-back therapy for long-term use in dysfunctional uterine bleeding and uterine fibroids. Br J Obstet Gynaecol 103: 18-21.

24. Adashi EY (1995) Long-term gonadotropin-releasing hormone agonist therapy: The evolving issue of steroidal "add-back" paradigms. Keio J Med 44: 124-132.

25. Chwalisz K, Surrey E, Stanczyk FZ (2012) The hormonal profile of norethindrone acetate: rationale for add-back therapy with gonadotropin-releasing hormone agonists in women with endometriosis. Reprod Sci 19: 563-571.
26. Hornstein MD, Surrey ES, Weisberg GW, Casino LA (1998) Lupron add-Back study group. Leuprolide acetate depot and hormonal add-back in endometriosis: a 12-monthstudy. Obstet Gynecol 91: 16-24.

27. DiVasta AD, Feldman HA, Gallagher SJ, Stokes NA, Laufer MR, et al. (2015) Hormonal add-back therapy for females treated with gonadotropin-releasing hormone agonist for endometriosis: A randomized controlled trial. Obstet Gynecol 126: 617-627.

Copyright: (2019 Aljasser R. This is an open-access article distributed under the terms of the Creative Commons Attribution License, which permits unrestricted use, distribution, and reproduction in any medium, provided the original author and source are credited. 